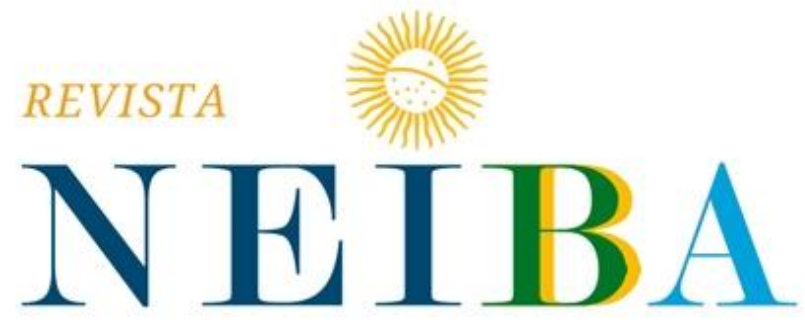

CADERNOS ARGENTINA-BRASIL
Volume 8, 2019, p. 01-23

DOI: 10.12957/neiba2019.43341|e43341|ISSN: 2317-3459

\title{
LA CARRERA GEOESTRATÉGICA POR LA TOMA DE POSICIONES EN EL OCÉANO ÍNDICO
}

A Corrida Geoestratégica para a tomada de Posições no Oceano Índico

\section{Bianca Agostina Concatti ${ }^{1}$}

${ }^{1}$ Grupo de Estudios sobre India y El Sudeste Asiático de Rosario (GEIRSA-PRECSUR), Facultad de Ciencia Política y Relaciones Internacionales, Universidad Nacional de Rosario (UNR), Rosario, Santa Fe, Argentina. E-mail: biancaconcatti@hotmail.com. ORCID: https://orcid.org/0000-0001-8878-7319

Recebido em: 14 jun. 2019 | Aceito em: 20 set. 2019

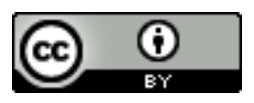

Esta obra está licenciado com uma Licença Creative Commons Atribuição 4.0 


\section{RESUMEN}

El viraje del Asia-Pacífico al Indo-Pacífico en los últimos años ha puesto al Océano Índico en el centro del escenario mundial, donde las grandes potencias navales se están disputando un lugar privilegiado para obtener los beneficios que trae aparejado el control de las rutas comerciales de dicho océano. En este sentido, China está desafiando a los Estados Unidos y a sus aliados, en un intento por establecer las reglas de juego del sistema marítimo internacional y conseguir la supremacía de los mares. Para ello está proyectando ambiciosas iniciativas y megaproyectos marítimos, junto con prácticas navales, que resultan una amenaza para el resto de los actores. En consecuencia, Estados Unidos, India y Japón están desarrollando sus propios planes estratégicos para crear un muro de contención al avance chino.

Palabras-clave: Océano Índico, geoestrategia, megaproyectos marítimos.

\section{RESUMO}

A mudança da Ásia-Pacífico para o Indo-Pacífico nos últimos anos colocou o Oceano Índico no centro do cenário mundial, onde as grandes potências navais lutam por um lugar privilegiado para obter os benefícios que vêm com o controle das rotas comerciais, do referido oceano. Nesse sentido, a China está desafiando os Estados Unidos e seus aliados na tentativa de estabelecer as regras do sistema marítimo internacional e alcançar a supremacia dos mares. Para isso, está planejando iniciativas e megaprojetos marinhos ambiciosos, juntamente com práticas navais, que são uma ameaça para os demais. Como resultado, os Estados Unidos, a Índia e o Japão estão desenvolvendo seus próprios planos estratégicos para conter o avanço chinês.

Palavras-chave: Oceano Índico, geoestratégia, megaprojetos marítimos 


\section{INTRODUCCIÓN}

El dominio de los océanos ha marcado las relaciones de poder entre las grandes potencias desde el siglo XVI. Históricamente el poder sobre los océanos ha sido de vital importancia para el desarrollo económico y comercial de las civilizaciones, pero también ha servido como un gran componente militar para desarrollar la capacidad de crear, explotar y defender los intereses marítimos de las naciones tanto en tiempos de paz como de guerra (HILL; 1990, 32). Si observamos el pasado, es claro ver como Portugal, Holanda, España y Gran Bretaña -y actualmente Estados Unidos- fueron importantes potencias navales en sus épocas de esplendor. Su dominio marítimo, expresado a través del despliegue de flotas, bases y alianzas navales, fue un aspecto fundamental para posicionarse como hegemones en el sistema internacional imperante en cada momento de la historia.

Asimismo, el peso de la geografía ha jugado un rol indiscutible en la configuración de las relaciones internacionales. Teniendo en cuenta que los océanos ocupan la mayor parte de la superficie del planeta, estos han sido -y son también hoy en día- escenario de la puja por el poder y por el intento de establecer el status quo del orden internacional. De esta manera, mientras que el Océano Atlántico se configuró como el centro de las relaciones internacionales hasta mediados del siglo XX, desde fines de la Segunda Guerra Mundial el Océano Pacífico ha emergido como un espacio de importancia geopolítica y ha ido ganando relevancia con el auge económico de la región del Asia-Pacífico. No obstante, hoy el área que está generando mayores controversias es el Océano Índico, donde las grandes potencias marítimas están disputando su control en pos de su envergadura estratégica y de los beneficios que traería aparejado la vigilancia de las rutas comerciales que atraviesan estas aguas.

Desde la mitad del siglo pasado Estados Unidos se constituyó como el gendarme del Océano Índico tras la retirada del Reino Unido de la región. Empero, esta posición exclusiva que ha tenido la potencia norteamericana gracias a su V Flota Naval y a su base aérea y naval en la isla Diego García, está siendo disputada por el ascenso de nuevas potencias navales, principalmente por China. 
El ascenso del gigante asiático en la estructura de poder mundial y su interés por extender su influencia en la región y en el mundo, constituye actualmente el foco central de preocupación para las potencias tradicionales, sobre todo para los Estados Unidos; pero a su vez, no deja de ser una gran amenaza para otros países de Asia como India y Japón. Como consecuencia de ello, se está dando en la región del Indo-Pacífico una proyección de iniciativas y megaproyectos marítimos, junto con prácticas navales, que están alterando el entorno geopolítico y la seguridad marítima del Océano Índico, convirtiéndolo en un área candente donde podrían desatarse futuros enfrentamientos.

Ante este contexto, el presente artículo pretende, en primer lugar, dar cuenta de la importancia geoestratégica que posee el Océano Índico y la región circundante para las relaciones internacionales del siglo XXI. Y en virtud de ello, analizar las implicancias de las acciones emprendidas por las grandes potencias regionales y extrarregionales interesadas en expandir su influencia en el área. De esta manera, se busca demostrar como la supremacía sobre los océanos sigue siendo, aún hoy en día, un aspecto fundamental para erigirse como una gran potencia mundial y un recurso de poder indispensable a la hora de posicionarse en el sistema internacional.

\section{LA IMPORTANCIA GEOESTRATÉGICA DEL OCÉANO ÍNDICO}

El Océano Índico es el tercero en extensión del planeta -luego del Pacífico y del Atlántico- y recibe su nombre por la India, que ocupa una posición central en su parte septentrional. El mismo se extiende desde las costas de África del Este pasando por Medio Oriente, Asia del Sur y el Sudeste Asiático hasta Australia. Su valor geoestratégico reside en ser una gran vía de comunicación que conecta a los países productores de hidrocarburos del Golfo Pérsico y de materias primas de África con las zonas industrializadas del Sudeste Asiático y los mercados de Europa. En concordancia con esto, cabe destacar que en el Índico se encuentra una de las mayores reservas de petróleo y gas del mundo, sumado a que por allí circula el $80 \%$ de los flujos energéticos globales, lo que supone la mitad del tráfico mundial de contenedores. Además, esta 
región abarca una población de 6.100 millones de personas, es decir, el 76,9\% del total global (Navaridas, 2018).

Adicionalmente a los recursos hidrocarburíferos, este océano también es rico en recursos hídricos y biológicos. Entre ellos cabe destacar los recursos minerales, pesqueros y de los fondos marinos, que abarcan desde depósitos de sulfuro, que contienen metales preciosos como plata, oro, cobre, manganeso, cobalto y zinc, hasta nódulos de fósforo para fertilizantes (Chellaney, 2017).

Empero, el intento de los Estados ribereños, pero también de muchos países extrarregionales por acceder y beneficiarse de estos recursos está generando graves consecuencias en el ecosistema y en los Estados litorales que dependen en gran medida de los recursos marítimos para alimentar a sus poblaciones y proporcionar valiosos ingresos de exportación (de Silva-Ranasinghe, 2011). La actividad humana está produciendo una enorme degradación ambiental en el Océano Índico como causa principalmente de la sobrepesca, la sobreexplotación de los recursos naturales y la contaminación, que contribuyen al agotamiento de muchas especies y a la desestabilización de ecosistemas enteros. No es menor mencionar que el Océano Índico es uno de los océanos más contaminados del mundo, como producto de las acciones de los buques mercantes, pesqueros y militares, y de las grandes cantidades de tóxicos de aguas residuales, perforaciones, minería y vertido de residuos químicos, tanto industriales como hospitalarios, que se depositan en el mismo (Torres Moral, 2017).

En este contexto, ante el afán de ocupar un espacio privilegiado en el acceso a los recursos y vías marítimas y, como consecuencia de la laxa jurisdicción de la mayoría de los países costeros, el Océano Índico se caracteriza también por ser escenario de un elevado nivel de actividades ilícitas de todo tipo. Entre estas, además de la pesca ilegal, cabe destacar la piratería marítima, el contrabando de armas, drogas y productos falsificados, y el tráfico de personas -sobre todo en algunos países del Sudeste Asiático que son destinos muy populares para el turismo sexual-. Como consecuencia de ello, en este océano circulan grandes redes organizadas de trata de blancas y organizaciones de crimen organizado transnacional (Torres Moral, 2017). 
Sumado a esto, Zbigniew Brzezinski ${ }^{1}$ ha calificado a la región del Índico como el "arco de crisis", por ser el área más inestable del planeta y el lugar preferido de despliegue del terrorismo islámico. Esta amplísima zona, que abarca países sumamente diversos, se destaca por el fervor religioso, el desequilibrio y la fragilidad de las estructuras sociales y políticas, y por los conflictos étnicos internos. Otro dato que no es menor, es que aquí se emplazan dos países con armas nucleares enfrentados desde su nacimiento, que son India y Pakistán² (Muñoz-Alonso, 2014).

Todos estos aspectos representan un gran desafío para la seguridad marítima del Océano Índico y para la soberanía marítima de los países ribereños, que a mayor escala significa un importante reto para la gobernanza oceánica global del siglo XXI. No cabe duda que la importancia geoestratégica del Índico está definiendo gran parte de los intereses de las naciones que apuntan a convertirse en superpotencia, para lo cual están proyectando ambiciosos planes estratégicos marítimos.

\section{LA PRESENCIA DE ACTORES INTERNACIONALES EN EL OCÉANO ÍNDICO}

El imperio sobre el Océano Índico estuvo hasta poco después de mitad del siglo pasado controlado por el Reino Unido, considerado el "Señor de los mares" (Sea Lord). Dicho océano fue algo así como un "lago británico" durante el siglo XIX y comienzos del siglo XX, bajo la llamada 'Pax Britannica3', que era respaldada por la Royal Navy ${ }^{4}$ y la diplomacia de las cañoneras ${ }^{5}$. Pero con la independencia de las colonias británicas (India y Pakistán en 1947, Sri Lanka y Myanmar en 1948, Omán en 1951, Malasia en 1957, Somalia en 1960, Tanzania en 1961, Singapur y Kenia en 1963) y la retirada de

\footnotetext{
1 Zbigniew Kazimierz (1928-2017) fue un politólogo de origen polaco que ocupó la función de consejero de Seguridad Nacional durante el gobierno del presidente de Estados Unidos Jimmy Carter.

2 El conflicto entre India y Pakistán se remonta a 1947, año en que ambos Estados obtuvieron su independencia del Reino Unido. Desde ese entonces la disputa está centrada en la región de Cachemira, que ambos países reclaman como propia.

${ }_{3}^{3}$ Período de dominio mundial británico comprendido entre 1815 y 1914, que se caracterizó por una gran prosperidad económica, sustentado en los principios de la revolución industrial, la paz mundial y la fraternidad en todo el Imperio. ${ }^{4}$ La Royal Navy o Marina Real británica es la rama de guerra naval de las Fuerzas Armadas británicas.

${ }^{5}$ La diplomacia de las cañoneras era una estrategia que consistía en presionar a un país menos desarrollado o poderoso enviando un buque cañonero al mar de dicho país, para bombardear sus puertos y obligarlo a aceptar las condiciones que establecía la potencia.
} 
ciertos dominios de ultramar (Zanzíbar en 1963, las islas Maldivas en 1965 y Mauricio en 1968) el Reino Unido fue abandonando su predominio en la región (Scott, 2018, p. 2). Esto, sumado a la decisión británica de retirarse del este del Canal de Suez en 1968 y los sucesos políticos y militares posteriores, llevaron a la Armada norteamericana a asumir responsabilidades triocéanicas -como suma de su participación en los océanos Atlántico y Pacífico- que si bien ya existían, antes eran compartidas con los británicos (Scheihing Navarro, 1982, p. 301). De esta manera, Estados Unidos se convirtió en el "gendarme" del Índico gracias a su V Flota Naval, su base aérea y naval en la isla Diego García ${ }^{6}$ y los numerosos pactos de ayuda mutua y cooperación militar que tiene con varios países de la región (Gimenéz, 2012).

Si bien durante el período de Guerra Fría también tuvieron presencia en el área las Armadas de Francia, Gran Bretaña, la Unión Soviética y Australia, y en menor medida las de India, Sudáfrica, Irán y Pakistán, es indiscutible que el poderío norteamericano logró disuadir la amenaza soviética y controlar toda la franja marítima del Índico bajo su hegemonía (Scheihing Navarro, 1982, p. 314). Esta supremacía se extendió a otras partes del globo, tanto a través de su presencia militar como mediante la proliferación de empresas multinacionales con las que buscó promover y asegurar sus intereses económicos y políticos capitalistas. Este objetivo se consignó finalmente con la caída del muro de Berlín y el fin de la Guerra Fría en 1989, tras el cual emergió un orden internacional unipolar liderado por los Estados Unidos.

Sin embargo, con la crisis financiera internacional del 2008 se produjo un declive relativo del poder norteamericano generando un vacío de poder que permitió el ascenso de nuevas potencias emergentes. Ante este nuevo contexto, en los últimos años se ha acelerado el traspaso de poder e influencia de Occidente a Oriente inaugurando con ello un nuevo orden mundial multipolar, en el cual queda en evidencia que si bien Estados Unidos seguirá siendo una superpotencia durante algunas décadas, ya no puede resolver por sí solo los grandes retos globales. Este nuevo escenario

\footnotetext{
6 La isla Diego García, ubicada en el centro del Océano Índico, pasó a disposición de EE.UU. en 1966 cuando el Reino Unido se la arrendó por 50 años para que la Administración Johnson instalara allí una base aérea y naval. Actualmente aloja a unos 2.200 soldados permanentes, dispone de un puerto para 30 barcos de guerra, un vertedero nuclear, una estación de satélites espía, centros comerciales, bares y un campo de golf. Tras la ocupación estadounidense los lugareños fueron desalojados de la isla.
} 
internacional se caracteriza por ser más dinámico y abierto, en tanto la participación de nuevos actores ha contribuido a que el centro de gravedad de la política y la economía mundial se traslade del Atlántico al Indo-Pacífico (Giné Daví, 2010). En consecuencia, con el ascenso de India y China como potencias emergentes, el Océano Índico se ha convertido en un espacio de vital importancia para controlar las principales rutas marítimas por las cuales se comercializan las materias primas y los recursos energéticos indispensables para el sustento de sus industrias y para abastecer el creciente consumo de las clases medias en expansión.

En relación con ello, hay que tener en cuenta que China es el país más poblado del mundo y el mayor importador y consumidor de hidrocarburos del planeta; mientras que India ocupa el segundo puesto a nivel mundial en cuanto a población y el cuarto en consumo de petróleo. Ambos países se abastecen a través de las rutas de este océano, ya que alrededor del $70 \%$ de la producción petrolífera global se halla en los países de Oriente Próximo y el 40\% del gas del mundo pertenece a países de Asia central. India además, importa carbón de varios países de la región, y a esto hay que sumar que alrededor del 30\% del comercio mundial se localiza en los puertos del Índico. Esto está llevando a que ambas economías se disputen la preeminencia en este vasto océano y busquen asegurar las rutas de tránsito marítimo, tanto para la importación de suministros energéticos claves para su economía, como para la exportación de bienes de consumo y maquinarias que constituyen el motor de su crecimiento económico (Malena, 2013, p. 30). Cabe agregar además, que el Océano Índico también es la vía de comunicación más rápida hacia los mercados del África Subsahariana que son cada vez más importantes tanto para China como para India (de Miguel Calabia, 2018).

No obstante, existen otros actores, tanto tradicionales como emergentes, con fuertes intereses en el área. Dentro de los primeros cabe mencionar la presencia significativa de Francia en los cuadrantes norte y suroeste del Océano Índico, donde posee bases navales ubicadas en Djibouti, Reunión y Abu Dhabi. De igual modo, es clave la existencia de barcos franceses y españoles frente al cuerno de África como consecuencia de los derechos de acceso a la pesca plasmados en los acuerdos entre la Unión Europea y los Estados africanos (de Silva-Ranasinghe, 2011). El otro Estado 
europeo que ha retornado a estas aguas en los últimos años es el Reino Unido. En 2017 el entonces secretario de Asuntos Exteriores de Gran Bretaña, Boris Johnson, señaló que el país decidió restaurar su presencia militar al este del Suez con un compromiso de tres mil millones de libras durante diez años y una instalación de apoyo naval en Bahrein, formada por dos nuevos portaaviones de la Armada Real. Así mismo, Johnson remarcó que la defensa de los intereses geoeconómicos británicos requiere del estacionamiento y despliegue naval para salvaguardar las líneas marítimas de comunicación y los puntos de estrangulamiento dentro y fuera del Océano Índico (Scott, 2018, p. 1-2).

Respecto a los actores no tradicionales en la zona, hay que destacar el caso de Japón que depende en gran medida de la región del Océano Índico para el suministro de energía y materias primas, por lo que en los últimos años ha incrementado considerablemente su presencia en estas aguas (Chellaney, 2017). Así mismo, otros países como Irán, Pakistán e incluso Rusia también se están esforzando en fortalecer sus posiciones y aumentar su capacidad para contrarrestar las amenazas potenciales que les plantea Estados Unidos y sus aliados (Torres Moral, 2017).

Por otro lado, no podemos dejar de mencionar el rol que juegan otros actores internacionales no estatales, como las empresas multinacionales, principalmente aquellas que se dedican a la explotación y comercialización de recursos energéticos. De hecho, el gobierno estadounidense ha tendido un corredor de seguridad para el petróleo y el gas natural desde la cuenca del Mar Caspio en Asia Central, pasando por Afganistán y Pakistán hasta el Mar Arábigo, gracias a la instalación y logística de muchas de sus empresas multinacionales (Dufour; 2010). Pero cabe aclarar que esta táctica no es exclusiva de los Estados Unidos, dado que muchos otros países están operando de la misma manera.

El resto de los actores no estatales, como ya se mencionó previamente, están vinculados a actividades ilícitas, como ser grupos terroristas, piratas y organizaciones criminales. 


\section{LA CARRERA ARMAMENTÍSTICA Y LOS MEGAPROYECTOS MARÍTIMOS EN EL OCÉANO ÍNDICO}

Desde 1945 el poder marítimo y naval de los Estados Unidos se ha ido acrecentando de manera ascendente como una forma de afirmar su hegemonía a nivel global. Las administraciones norteamericanas han sabido reconocer que garantizar la salida a los mares es un recurso geoestratégico de disponibilidad militar que le ha permitido a la potencia del Norte convertirse en un líder marítimo mundial. Es por eso que su poder marítimo es el resultado de una evolución lenta y constante de las capacidades navales, producto de la incorporación de nuevas tecnologías y de un presupuesto dedicado exclusivamente al gasto militar total, que llegó a ocupar el 9\% del PBI del país en los años 1960 (Grupo Banco Mundial, 2017)․ Esto refleja que para los Estados Unidos el desarrollo naval ha sido un aspecto esencial de su política exterior; el cual es justificado bajo el discurso de la defensa de la libre navegación de los mares y la libertad de comercio (Bonilla y Carrillo, 2015).

Siguiendo esta lógica, los Estados Unidos han visto al Océano Índico como un océano estratégico para ejercer su preeminencia y control en la zona. Después de la salida británica de la región, las fuerzas norteamericanas se extendieron en dicho océano gracias a su V Flota Naval, cuya sede se encuentra en Bahrein y utiliza la base en la isla Diego García como un centro logístico para sus operaciones en el área. Esta base no es sólo una importante herramienta de influencia militar de los Estados Unidos en el Índico -desde la que controla Medio Oriente y la mitad de Asia y África-, sino también, una de las mayores bases militares del mundo fuera de su territorio nacional; que además sirve como punto de partida de muchas de las últimas operaciones que los Estados Unidos han Ilevado a cabo en Irak y Afganistán a principios de este siglo. Así mismo, cabe mencionar que la potencia del Norte ha desplegado desde el 2004 varias fuerzas de tarea navales importantes, incluida la Fuerza de Tarea Combinada 152, que tiene como objetivo proteger el flujo de petróleo a través del Golfo Pérsico, y la Fuerza

\footnotetext{
${ }^{7}$ Los datos sobre gastos militares incluyen todos los gastos corrientes y de capital relativos a las Fuerzas Armadas, incluidas las fuerzas de mantenimiento de la paz; los ministerios de defensa y demás organismos de gobierno que participan en proyectos de defensa; el personal militar y civil; las operaciones, mantenimiento, compras, investigaciones y desarrollos militares; y la ayuda militar.
} 
de Tarea Combinada 150, que tiene por fin contrarrestar la piratería del Golfo, de Omán a Kenia (de Silva-Ranasinghe, 2011). Los Estados Unidos también cuentan con otras bases navales colindantes como la de Darwin en Australia y en las Islas Cocos; bases militares permanentes en Singapur, Djibouti, Yemen, Omán, Bahrein, Qatar, Kuwait y Pakistán, y bases aéreas en Afganistán, Kirguizistán, Uzbekistán y Turkmenistán (Arancón, 2014, p. 3).

Esta expansión de buques, bases navales, terrestres y aéreas y las alianzas militares que los Estados Unidos han extendido por todo el mundo desde el siglo pasado, le han permitido forjar el mapa político y proyectar su poder militar a nivel global, de modo tal que aún hoy en día sigue ocupando uno de los primeros puestos en cuanto a capacidad y gasto militar.

A pesar de ello, la posición privilegiada que ocupó Estados Unidos hasta la primera década de este siglo en el Océano Índico comenzó a ser desafiada con el ascenso de las nuevas potencias emergentes, particularmente por China; y por el relativo declive de poder de Washington tras la crisis financiera internacional del 2008 que trasladó las prioridades de su agenda hacia otros temas y regiones. Ante este vacío de poder, se puede ver claramente como hoy en día Beijing sigue más de cerca una lógica geoeconómica en busca de un lugar privilegiado en la económica mundial. De hecho, según Giné Daví (2010) el comunismo chino se ha transformado en un capitalismo confuciano sin pluralismo político que está sacando un gran provecho de la globalización económica.

En relación a su poder marítimo es relevante mencionar que en 2010 el gigante asiático pasó a ocupar el primer lugar en lo que refiere a la industria naval, al adquirir el astillero más grande del mundo con capacidad para construir navíos de alta complejidad y portaaviones. Si bien el gasto militar representa sólo entre un 1,5\% y un 3\% del PBI del país, hay que resaltar que mientras que la economía china llegó a crecer al 10\% anual, su gasto militar lo hizo al 15\%. Esto es producto de una profunda reforma militar que se viene dando desde la asunción del presidente Xi Jinping, que apunta a invertir más en innovación y tecnología para modernizar las fuerzas armadas, principalmente en las áreas naval, aérea y de misiles (Ankov, 2017). 
Como consecuencia, China viene desarrollando e incrementando su industria de construcción naval y ha adoptado una vocación marítima militar, fruto de la confluencia de factores económicos, de seguridad y diplomáticos. Así mismo, se ha abocado a la construcción de una armada oceánica; está proyectando su capacidad naval más allá de su Zona Económica Exclusiva; y ha irrumpido en la porción meridional del Mar del Sur de la China, el Estrecho de Malaca y el Océano Índico, áreas de influencia de competidores regionales aliados a los Estados Unidos (Malena, 2013, p. 35). Según informes del Pentágono, China está fabricando gran armamento y equipamiento marítimo que incluye portaaviones, corbetas, drones marítimos, minas, submarinos, sensores, aviación naval, medios de guerra electrónica y buques anfibios. De igual modo, el país ha hecho considerables inversiones en el desarrollo de la logística naval, la formación de marineros y doctrinas militares (Ankov, 2017). Otro informe presentado en 2018 por el Capitán de la U.S. Navy, James Fanell, ante el Congreso de los Estados Unidos, señala que la Armada de China ya supera a la de Estados Unidos en varios aspectos. Por ejemplo, China tiene desplegados 330 buques y 66 submarinos; mientras que los Estados Unidos tienen actualmente un total de 211 buques y 72 submarinos (Lima, 2018).

Por otro lado, hay que señalar que históricamente la estrategia naval de China fue poco ambiciosa y se concentró más bien en crear una defensa costera -que imitaba a la escuela naval soviética-, lo que se conoció como la "Gran Muralla del mar". Sin embargo, la creciente actividad de China refleja un cambio estratégico de "defensa de aguas marinas" a "protección de mar abierto", cuyo objetivo es salvaguardar sus intereses comerciales y energéticos (Chellaney, 2017). Para ello, China está desarrollando lo que se conoce como una "Marina de aguas azules", es decir, una Marina con capacidad interoceánica, que cuenta, entre otras cosas, con portaviones y un grupo de navíos que los escolten y estén en condiciones de prestarles servicios logísticos (Roca, 2017). 
En relación con todo lo expuesto, en 2005 el gobierno de Beijing adoptó un concepto geopolítico conocido como la "Estrategia del Collar de Perlas"8, que consiste en un cerco estratégico compuesto por una red de relaciones militares y económicas en el Océano Índico. Esta iniciativa estableció una serie de bases navales, consideradas "perlas", para proteger la ruta por la que pasa el 90\% del crudo y la mayor parte de las mercancías que este país importa (Gimenéz, 2012). Estas instalaciones navales están ubicadas en los puertos de Gwadar en Pakistán, de Colombo en Sri Lanka, de Chittagong en Bangladesh y de Sittwe en Myanmar. Sin embargo, hasta el momento China sólo ha desarrollado puestos de avanzada para el abastecimiento de combustible y el mantenimiento de su Armada y flota mercante. No obstante, cabe aclarar que los puertos del Collar de Perlas tienen el potencial para llegar a ser bases navales en toda la expresión de la palabra, con capacidad de disuadir cualquier intento ofensivo de los demás actores, incluido los Estados Unidos (Salazar Camarillo, 2015, p. 2-3).

De la misma forma, el actual presidente de China, Xi Jinping, ha sido muy estratégico al tener en cuenta que sólo con el empleo del poder duro (hard power) no será suficiente para poder imponerse en la región. La creciente interdependencia económica del gigante asiático con la mayoría de los actores del Índico, hizo necesario reforzar una imagen de cooperación y diálogo, para disuadir la idea de que China podía ser una amenaza en la región. En este sentido, desde la asunción de Xi en 2013, los líderes del Partido Comunista chino se han enfocado arduamente en mostrar a China como un actor responsable en los asuntos globales y regionales, que busca promover la paz regional y mundial. Justamente en este contexto el mandatario chino presentó la iniciativa de la "Nueva Ruta de la Seda", más conocida en inglés como Belt and Road Initiative (BRI), que consiste en un megaproyecto de financiamiento de infraestructura que combina el uso del hard power con el soft power.

La Iniciativa de la Franja y la Ruta comenzó siendo una estrategia regional para la cooperación económica de China en Asia, África y Europa, pero luego se extendió también a Oceanía y América Latina. Desde la perspectiva china, este proyecto busca facilitar la conectividad, el comercio y el tránsito regionales a través de un esquema de

\footnotetext{
${ }^{8}$ El término fue acuñado en un primer momento por la consultora norteamericana Booz Allen Hamilton en 2004, y luego el gobierno de Beijing lo adoptó como propio y lo oficializó.
} 
desarrollo regional y la coordinación de políticas que generen contribuciones conjuntas y beneficios mutuos, con el objetivo de reportar ganancias a todos los participantes. Para ello, el gigante asiático ha puesto en marcha dos corredores: uno terrestre denominado "Franja Económica de la Ruta de la Seda", y otro marítimo, dado a conocer con el nombre de "Ruta Marítima de la Seda del Siglo XXI", que se extenderá desde el Mar de China Meridional hasta las aguas del Mar Mediterráneo, pasando por el Estrecho de Malaca, el Océano Índico, el Golfo Pérsico y el Mar Rojo, e interconectando alrededor de 20 países (Ranade, 2016).

La Ruta Marítima de la Seda apunta por una parte a construir una nueva forma de cooperación regional de seguridad marítima; aunque por otro lado, el objetivo geoestratégico del gigante asiático es garantizar el control de Beijing sobre las rutas comerciales marítimas más importantes y el abastecimiento ininterrumpido de materias primas. Como consecuencia, este corredor marítimo está fuertemente enfocado en la búsqueda de la supremacía marítima china y en la aspiración por desarrollar capacidades expedicionarias marítimas para operar en las aguas profundas de los océanos abiertos (Chellaney; 2017). Teniendo en cuenta estos objetivos, el sueño de China de construir una "asociación azul" a través de la Ruta Marítima de la Seda es un medio para lograr su objetivo más amplio de asegurarse una posición en el hegemonía marítima mundial (Jash, 2017, p. 76-80).

En relación al Océano Índico, la Ruta Marítima de la Seda no representa un desarrollo per se, puesto que el gigante asiático ya tenía presencia en la región -como bien mencionamos- con la estrategia del Collar de las Perlas. Por consiguiente, el aporte más significativo de este nuevo plan estratégico tiene que ver con que la apuesta ahora está aumentando, en busca no sólo de ampliar la permanencia en el área, sino también los intereses estratégicos de esta potencia emergente. En virtud de ello, China está expandiendo rápidamente su presencia en el Océano Índico, gracias al establecimiento de nuevas bases militares, como la de Djibouti, que le permitirá lanzar operaciones navales alrededor del Cuerno de África. Así mismo, está realizando grandes inversiones en la construcción de nuevos puertos marítimos regionales en las islas Seychelles y Maldivas, en Hambantota en Sri Lanka y en Kyaukpyu en Myanmar, cuyo control se lo 
ha adjudicado producto de su arrendamiento (Chellaney, 2017). Cabe aclarar, que según el gobierno de Beijing, estas instalaciones no tendrán un uso propiamente militar, sino que estarán orientadas más bien hacia el uso comercial.

Con todo esto, aún queda mencionar un aspecto fundamental, si no el más importante, que ha llevado a China a concentrar su despliegue de fuerzas en el Índico. Este tiene que ver con el intento de disminuir su dependencia del Estrecho de Malaca, por el que actualmente se transportan cerca del $90 \%$ de su comercio marítimo y de los suministros de energía que importa. El Estrecho de Malaca es un punto de estrangulamiento entre Malasia, Singapur e Indonesia; los dos primeros países aliados de los Estados Unidos, que junto con el Reino Unido, Australia, Corea del Sur y Japón podrían proceder como una suerte de muro de contención del expansionismo chino, neutralizando una de las vías principales para el milagro industrial del gigante asiático (Sánchez Canóvas, 2017). Esta situación de fuerte dependencia que enfrenta Beijing con este corredor, ha sido denominada por Malcom Davis (2014) como el "Dilema de Malaca".

Ante esta situación, el gobierno de China está tratando de desarrollar una vía alternativa dentro del marco de la Nueva Ruta de la Seda, que tiene que ver con el "Corredor Económico Chino-Pakistaní" (CPEC, por sus siglas en inglés). La importancia de esta ruta terrestre -donde el gobierno chino ha colocado una enorme apuesta de 46.000 millones de dólares destinados al financiamiento de una serie de proyectos energéticos, de autopistas y ferrocarriles-, radica en que gracias al arrendamiento por 40 años del puerto de Gwadar, en Pakistán, las mercaderías chinas tendrán un rápido acceso a los mercados de África y Asia Occidental; mientras que el gigante asiático se asegurará el suministro de los recursos necesarios para su economía, evitando transitar por el Estrecho de Malaca. No obstante, cabe resaltar que la nueva política militar de Beijing prevé un aumento para los próximos años del $400 \%$ en sus dotaciones de personal para su Armada y una presencia permanente de sus barcos militares en Gwadar, como escolta de los buques mercantes chinos que operan en Medio Oriente (Sánchez Canóvas, 2017). 
Asimismo, hay que tener en cuenta que el gobierno de Beijing está poniendo toda su política exterior, y gran parte de su política doméstica, al servicio de esta ambiciosa iniciativa, apelando fuertemente a la diplomacia bilateral y multilateral, pero también a las presiones económicas, sobre todo de los países más pequeños. Si bien el relato chino sostiene que estas inversiones pretenden promover la integración con sus vecinos y afianzar nuevas alianzas, el verdadero fin de las mismas es en realidad neutralizar la estrategia estadounidense y de cualquier otro país competidor, para ampliar su influencia en el mundo y convertirse en el hegemón del siglo XXI.

En correlación con esto, la Administración Xi ha sabido aprovechar el cambio de gobierno en los Estados Unidos en 2017, sobre todo en un punto primordial, que tiene que ver con la decisión del presidente Donald Trump de retirarse del Acuerdo Transpacífico de Asociación Económica9 (TPP, por sus siglas en inglés), impulsado por el anterior presidente, Barack Obama. Esta resolución, según Navaridas (2018) marcó la interrupción de la primacía de los relatos geopolíticos occidentales y, como consecuencia, el despegue de visiones del mundo 'made in Asia'.

En congruencia, esta etapa que estamos atravesando, que muchos autores han denominado "el siglo de Asia", trae consigo grandes planes estratégicos diseñados por las potencias emergentes que apuntan a convertirse en líderes económicos, políticos y militares mundiales. Sin duda alguna, el megaproyecto de la Nueva Ruta de la Seda, que se inserta en la visión global del presidente Xi Jinping del "sueño chino"10, supone crear vínculos económicos, financieros, políticos y geoestratégicos que le proporcionen a China una red global de intereses consolidada para establecer las reglas del juego para las relaciones internacionales del siglo XXI.

No obstante, como se observó precedentemente, China no es el único país asiático interesado en extender su influencia en la región del Índico; existen otros actores regionales y extrarregionales que están proyectando su predominio en el área. Entre

\footnotetext{
9 El TPP es un Tratado de Libre Comercio entre varios países de la Cuenca del Pacífico, conformado por los países del Acuerdo Estratégico Trans-Pacífico de Asociación Económica (Brunéi, Chile, Nueva Zelanda y Singapur) al que se sumaron en 2008 Australia, Canadá, Estados Unidos, Japón Malasia, México, Perú y Vietnam. En enero de 2017 Estados Unidos anunció su retirada definitiva del tratado, aunque los once países restantes continuaron negociando el tratado, ahora conocido como TPP-11.

10 El "Sueño chino" es un concepto que propuso el presidente Xi Jinping, que consiste en pocas palabras, en lograr la gran revitalización de la civilización china, convirtiéndola en un país próspero y fuerte, y en una nación vigorosa y un pueblo feliz.
} 
ellos, India es uno de los Estados más preocupados por el avance chino, en tanto aprecia al Océano Índico como su esfera natural de influencia. En virtud de ello, Nueva Delhi viene desplegando una serie de iniciativas de índole diplomática y económica tendientes a mejorar los lazos con sus vecinos de Asia Meridional y del Sudeste Asiático. Asimismo, está desarrollando una destacable destreza de proyección naval, cuyo objetivo a corto plazo es conseguir una estrategia marítima autónoma. Esto está conduciendo a la India a impulsar un gran rearme naval, que la ha llevado a convertirse en el mayor importador de material defensivo del mundo, a la vez que está arrastrando a toda la región a una intensa carrera armamentística (Torres Moral, 2017).

En primer lugar, cabe destacar que India está desplegando su propia "Cadena de Perlas", que consiste en la proyección de puertos y otros acuerdos marítimos que tiene con distintos países de la región. Uno de sus pilares principales en el Índico es el puerto marítimo iraní de Chabahar, ubicado al sureste de Irán en el Golfo de Omán, que fue eximido de las sanciones a la compra de petróleo por la Administración Trump, y que le sirve a India como puerta de entrada a Asia Central. Nueva Delhi está invirtiendo en la construcción de una línea ferroviaria que va desde este puerto hasta Afganistán, lo que le permitirá eludir el paso por Pakistán para comercializar con este país (Fang, 2018). Hay que tener en cuenta que India y Pakistán son dos enemigos históricos, que aparte de haberse enfrentado en tres guerras -en 1947, 1965 y 1971-, al día de hoy no han podido saldar el conflicto por la soberanía de la región de Cachemira, que ambos países se adjudican como propia.

Por otra parte, una cuestión que tampoco es menor es que estos dos países poseen armas nucleares y ninguno de los dos Estados es firmante del Tratado de No Proliferación Nuclear (TNP) ni del Tratado sobre la Prohibición de las Armas Nucleares o de Prohibición de Ensayos Nucleares (CTBT). Tanto la India como Pakistán desarrollaron sus programas atómicos con finalidad militar en la clandestinidad; y aunque sostienen que su doctrina nuclear se basa en el principio de la disuasión mínima, es decir, para un uso defensivo, ambos países han estado ampliando considerablemente su arsenal de misiles nucleares en los últimos años (Padinger, 2019). Empero, es menester mencionar que la India supera con creces la capacidad militar y armamentística de Pakistán. De 
hecho, debido a su preocupación por mantener el control en el Océano Índico, Nueva Delhi ha generado un cambio en las capacidades de las armas nucleares desde tierra a mar, aumentado su competencia nuclear tripartita ${ }^{11}$ y sus capacidades navales fuera de proporción. Como resultado, el gobierno de Modi ha acelerado el enriquecimiento de uranio y material fisionable para producir mayor cantidad de armas nucleares y de mayor tamaño en el menor tiempo posible. De la misma manera, este país del sur de Asia está modernizando su marina a un ritmo acelerado y apunta a convertirse en una potencia militar ofensiva, para lo cual está construyendo submarinos con capacidad nuclear (Zahid y Ehtisham, 2015).

No obstante, al igual que China, India reconoce que sólo con el despliegue de hard power no es suficiente para imponerse en la región. Por esta razón, el gobierno de Nueva Delhi también está proyectando ciertos planes estratégicos y se ha incorporado a distintas iniciativas "made in Asia", junto con Estados aliados que buscan contener el avance chino. En este contexto, Japón -que también depende en gran medida de la región del Océano Índico para el suministro de energía y materias primas-, está igualmente incrementado su compromiso regional y viene desempeñando un papel más activo en la protección de estas rutas marítimas (Chellaney, 2017). Para ello ha impulsado una propuesta conocida como la "Estrategia de un Indo-Pacífico libre y abierto", que se trata de un programa de asistencia en infraestructuras con el apoyo del gobierno a través de préstamos en yenes. Esta iniciativa ha sido secundada por los Estados Unidos, Australia e India, que han hecho resurgir el famoso "Cuadrilatero de Seguridad", que se venía discutiendo de manera intermitente desde 2007. La conformación de esta alianza busca cooperar en pos de la libertad de navegación y el Estado de derecho, en lo que el Primer Ministro nipón, Shinzo Abe, llamó el "Diamante de seguridad democrática de Asia" (Arana, 2017).

Por otro lado, en virtud de estos acercamientos, en 2016 surgió -como contrapartida de la Belt and Road Initiative- el "Corredor de Crecimiento de Asia y África" (AAGC, por sus siglas en inglés), que es una iniciativa entre Japón y la India para promover la conectividad entre ambos continentes y alentar proyectos conjuntos en

\footnotetext{
${ }^{11}$ La India posee medios de lanzamiento terrestres, marítimos y aéreos, conocidos como "Triada nuclear".
} 
África. Esta propuesta combina la política de Tokio de la "Estrategia de un Indo-Pacífico libre y abierto" y la política del "Act East Policy"12 de Nueva Delhi. Los mandatarios sostienen que el AAGC se introdujo como una forma de promover inversiones en áreas prioritarias (desarrollo, infraestructura de calidad, conectividad institucional, capacitación y creación de capacidad, y cooperación de persona a persona) a través de la complementariedad entre India y Japón. Empero, se puede vislumbrar que esta plataforma económica multilateral servirá de base para la creación de un nuevo bloque de seguridad centrado en África, cuyo fin es contener de manera más completa a China en este continente, donde las tres potencias asiáticas tienen intereses estratégicos.

Cabe destacar que todos estos movimientos que vienen llevando adelante tanto Japón como India tienen la aprobación de los Estados Unidos, que ha estrechado la relación con dichos países a través de la firma de tratados estratégico-militares. Mediante estos pactos, Estados Unidos ha aumentado su cooperación militar proveyendo a los dos países asiáticos ayuda en materia de inteligencia naval, vigilancia, reconocimiento y ataques de precisión (Chellaney, 2017). Además, las Armadas de India y Estados Unidos participan anualmente desde 1992 de lo que se conoce como "Ejercicio Malabar", que es un ejercicio naval conjunto que se lleva a cabo en las aguas del Pacífico, al que se ha sumado la participación de Japón desde 2015 en virtud de mejorar la cooperación en materia de defensa naval (Arana, 2017). De esta manera, la Administración Trump pretende compensar la regresión de su presencia en Asia, dándole a India el rol de guardián en el Océano Índico, y a Japón en el Pacífico Norte.

\section{CONCLUSIÓN}

La relevancia geoestratégica del Océano Índico, por ser una de las principales rutas marítimas y comerciales de materias primas y recursos energéticos estratégicos, es un

\footnotetext{
12 El Act East Policy (AEP) o Política de Acción hacia el Este es una redefinición de la Look East Policy, que pone el acento en una política exterior y comercial más proactiva, dando un salto cualitativo en los vínculos de India con los países de la ASEAN, y extendiendo sus relaciones a Australia y el Pacífico-Sur. Además, incluye la apertura hacia otros temas, como los esfuerzos conjuntos para aumentar la conectividad física entre dichos países, proteger las líneas marítimas y coordinar actividades contra el terrorismo.
} 
aspecto fundamental para entender la puja por el poder de las grandes potencias, que conciben que el imperio y control de este océano es una condición indispensable para dominar la región. De hecho, en este contexto ha vuelto a resurgir la célebre máxima del geopolítico y geógrafo inglés Halford John Mackinder: "Quien gobierne Europa del Este dominará el Heartland; quien gobierne el Heartland dominará la Isla Mundial; quien gobierne la Isla Mundial dominará el mundo" (en Brzezinki, 1998, p. 47). Este postulado, ubica el Heartland en la zona comprendida de este a oeste entre el Yangtsé y el Volga y, de norte a sur entre el Ártico y el Himalaya; mientras que Isla Mundial se refiere a los países que se encuentran entre el Mar Báltico y el Mar Negro. Este espacio estratégicamente ubicado, debido a su accesibilidad desde el Océano Índico, a su imposibilidad de invadirlo completamente y a sus ingentes recursos continentales, tiene una importancia geoestratégica, en tanto su control -según Mackinder- significaría el dominio mundial. Esta premisa que ha sido tenida en cuenta por muchos estrategas, hoy funciona como pivote de la política marítima de las grandes potencias, que consideran que a través del control del Océano Índico podrán dominar Eurasia y hacerse de la supremacía global.

Para ello, los actores regionales y extrarregionales se han lanzado al mar con grandes estrategias navales y megaproyectos de infraestructura que están alterando el entorno geopolítico del Océano Índico y modificando la dinámica de toda la región (de Silva-Ranasinghe, 2011). El desarrollo de capacidades marítimas, tanto duras como blandas, es lo que les permitirá a las potencias desarrollar una estrategia marítima y militar, tanto en tiempos de paz como de guerra, para sentar las bases de la seguridad y estabilidad de sus intereses comerciales y energéticos.

A modo de conclusión, cabe destacar que hoy el Océano Índico se ha constituido como un escenario de disputas geopolíticas por la gobernanza oceánica por los beneficios que trae aparejado el control estratégico de sus aguas. En efecto, el expansionismo chino, tanto a través de su avanzada naval como a través de sus iniciativas de poder blando, es la principal amenaza que actualmente tiene en vilo a la región. Para contrarrestar estos efectos, India, Japón y Estados Unidos están actuando en conjunto con el fin de crear una especie de contención al avance del gigante asiático. 


\section{REFERENCIAS BIBLIOGRÁFICAS}

ANKOV, Vitaly (2017); "La flota china, 'dando la lata' a EEUU en el océano mundial". Sputnik Mundo. Moscú, Rusia. Disponible en https://mundo.sputniknews.com/defensa/201709201072514837-oceano-potencianaval-armada-china/

ARANA, Ismael (2017); "Una estrategia Indo-Pacífica". El Mundo Internacional. Unidad Editorial. Madrid, España. Disponible en https://www.elmundo.es/internacional/2017/11/10/5a048f9bca4741237b8b460b.html

ARANCÓN, Fernando (2014); "El Collar de las Perlas de China: geopolítica en el Índico". El Orden Mundial en el siglo XXI. Creative Commons BY-NC-ND. Disponible en https://elordenmundial.com/el-collar-de-perlas-chino/

BONILLA, Henry y CARRILLO, Verónica (2015); “El Poder Marítimo como instrumento geopolítico para alcanzar el poder en el siglo XXI". Vox Politikon. Disponible en https://voxpolitikon.wordpress.com/2015/04/04/el-poder-maritimo-comoinstrumento-geopolitico-para-alcanzar-el-poder-en-el-siglo-xxi/

BRZEZINKI, Zbigniew (1998); “El gran tablero mundial. La supremacía estadounidense y sus imperativos geoestratégicos". Ed. Paidós 2007. Barcelona, España.

CHELLANEY, Brahma (2017); "Democratic powers must intensify Indian Ocean cooperation". Nikkei Asia Review. Disponible en https://chellaney.net/2017/09/29/democratic-powers-must-intensify-indian-oceancooperation/

DAVIS, Malcom (2014); "China's 'Malacca Dilemma' and the future of the PLA". The Asia Dialogue. Asia Research Institute, University of Nottingham. Disponible en https://theasiadialogue.com/2014/11/21/chinas-malacca-dilemma-and-the-future-ofthe-pla/

DE MIGUEL CALABIA, Emilio (2018); "El Indo-Pacífico: lo que hay detrás del concepto". Publicado en Asia-Pacífico, Firmas invitadas. Real Instituto Elcano. Elcano Royal Institute. Madrid, España Disponible en https://blog.realinstitutoelcano.org/el-indo-pacifico-loque-hay-detras-del-concepto/

DE SILVA-RANASINGHE, Sergei (2011); "Why the Indian Ocean Matters". The Diplomat. Disponible en https://thediplomat.com/2011/03/why-the-indian-ocean-matters/

DUFOUR, Jules (2010); "La Red Mundial de Bases Militares de los Estados-Unidos". Global Research, Centre for Research of Globalization (CRG). Quebec, Canadá. 
Disponible en https://www.globalresearch.ca/la-red-mundial-de-bases-militares-de-losestados-unidos/21173

FANG, Frank (2018); "India aumenta la presencia naval en el Océano Índico para contrarrestar a China”. La Gran Época. Disponible en

https://www.lagranepoca.com/news/392116-india-aumenta-la-presencia-naval-en-eloceano-indico-para-contrarrestar-a-china.html

GIMENÉZ, IvÁn (2012); "El océano Índico: escenario clave de la geopolítica mundial”. Huffpost, Edition ES. Disponible en https://www.huffingtonpost.es/ivan-gimenez/eloceano-indico-escenari_b_1874471.html

GINÉ DAVÍ, Jaume (2010); “Barack Obama apuesta por Asia-Pacífico". Estudios de Política Exterior N51. Asociación de Revistas Culturales de España (ARCE). Disponible en https://www.politicaexterior.com/articulos/economia-exterior/barack-obamaapuesta-por-asia-pacifico/

GRUPO BANCO MUNDIAL (2019); "Gasto militar (\% PBI) Estados Unidos". Disponible en https://datos.bancomundial.org/indicador/MS.MIL.XPND.GD.ZS?locations=US

HILL, Richard (1990); "Estrategia Marítima para potencias medianas". Instituto de Publicaciones Navales. Buenos Aires, Argentina.

JASH, Amrita (2017); "Djibouti: A Roadway to China's "Indian Ocean Dream". En Maritime Perspectives 2017. National Maritime Foundation. Nueva Delhi, India.

LIMA, Lioman (2018); "El plan naval de China para superar a la Armada de Estados Unidos y controlar el Pacífico en 2030". BBC Mundo. Disponible en https://www.bbc.com/mundo/noticias-internacional-44284609

MALENA, Jorge E. (2013); “La protección del comercio marítimo por parte de China: ¿conflicto en el horizonte con la India?". En Publicación Voces en el Fénix. Revista del Plan Fénix año $4 N^{\circ}$ 26. Facultad de Ciencias Económicas, Universidad de Buenos Aires. CABA.

MUÑOZ-ALONSO, Alejandro (2014); "Arco de crisis". El Imparcial. Editorial Imparcial de Occidente SA. Madrid, España. Disponible en

https://www.elimparcial.es/noticia/28293/opinion/arco-de-crisis.html

NAVARIDAS, Fernando Alonso (2018); "Iniciativas Indo-Pacíficas". Estudios de Política Exterior $N^{\circ} 184$. Asociación de Revistas Culturales de España (ARCE). Disponible en https://www.politicaexterior.com/articulos/politica-exterior/iniciativas-indo-pacificas/

PADINGER, Germán (2019); "Cómo es el temible arsenal nuclear de India y Pakistán". Infobae. Disponible en https://www.infobae.com/america/mundo/2019/02/27/comoes-el-temible-arsenal-nuclear-de-india-y-pakistan/ 
RANADE, Jayadeva (2016); "Can China realise its One Belt, One Road dream?". Hindustan Times. Disponible en https://www.hindustantimes.com/analysis/can-chinarealise-its-one-belt-one-road-dream/story-Vm2Gkc2jxtwr2xqOI1BsyM.html

ROCA, Mariano (2017); "China y su "espacio marítimo vital". Infobae. Disponible en https://www.infobae.com/def/internacionales/2017/12/29/china-y-su-espaciomaritimo-vital-2/

SALAZAR CAMARILLO, Víctor M. (2015); "El Collar de Perlas: Entre la expansión naval de China en el Océano Índico y una nueva Ruta de la Seda". Universidad Nacional Autónoma de México.

SÁNCHEZ CÁNOVAS, Manuel (2017); "La estrategia china del Collar de las Perlas para ganar la batalla comercial". El Debate de Hoy. Disponible en https://eldebatedehoy.es/economia/collar-de-perlas/

SCHEIHING NAVARRO, Rubén (1982); "El Océano Índico. Un desafío estratégico". Revista de Marina. Disponible en https://revistamarina.cl/revistas/1982/3/scheihing.pdf SCOTT, David (2018); "Britain Returns to the Indian Ocean?". The Round Table. The Commonwealth Journal of International Affairs. Disponible en https://www.tandfonline.com/doi/full/10.1080/00358533.2018.1476096

TORRES MORAL, C. (2017); “El Índico: un océano de superlativos". Reality Shock. Disponible en https://larealidadsuperaalaficcion.wordpress.com/2017/04/17/oceanoindico/

ZAHID, Ahsan Ali y EHTISHAM, Hasan (2015); "Indian Ocean: A zone of benefits or conflicts?". Foreign Policy News. Disponible en http://foreignpolicynews.org/2015/07/10/indian-ocean-a-zone-of-benefits-or-conflicts/ 